\title{
Remote sensing of water quality index for irrigation usability of the Euphrates River
}

\author{
H. S. Al-Bahrani ${ }^{1}$, K. A. Abdul Razzaq ${ }^{2}$ \& S. A. H. Saleh ${ }^{3}$ \\ ${ }^{I}$ Civil Engineering Department, University of Kufa, Iraq \\ ${ }^{2}$ Water Resources Engineering Department, University of Baghdad, Iraq \\ ${ }^{3}$ Physics Sciences Department, University of Nahrain, Iraq
}

\begin{abstract}
The aim of this paper is to study the water quality indices and their classifications for irrigation use at many stations along the Euphrates River inside the Iraqi lands and to try to correlate the results with the satellite image analyses for the purpose of making a colored model for the Euphrates that can be used to predict the quality classifications of the river for irrigation use at any point along the river. The Bhargava method was used to calculate the water quality index for irrigation use at sixteen stations along the river from its entrance to the Iraqi land at Al-Qaim in Anbar governorate to its union with the Tigris River at Qurna in Basrah governorate. Coordinates of the sixteen stations of the Euphrates River were projected at the mosaic of Iraq satellite image which was taken from LANDSAT satellite for bands 1,2 and 3.

It was noticed that there was a strong negative correlation between the water quality index and the digital numbers at band 2 for the mosaic satellite image. A regression model was built between the water quality index at December, 2009 and the digital number at band 2 so as to build a colored model which was used to predict a water quality classification for irrigation use at any point along the river.

Keywords: water quality index, irrigation usability, Bhargava, Euphrates River, digital satellite image.
\end{abstract}

\section{Introduction}

Of all natural resources, water is unarguably the most essential and precious. Life began with water, and life is nurtured by water. There are organisms, such 
as anaerobes, which can survive without oxygen, but no organism can survive without water. Surface waters face an increasing problem through the disposal of pollutants due to the rapid growth of industrial and municipal activities because of the increase in population growth as well as the increase of land drainage due to agricultural activities. Thus, there has been an increasing concern about water quality all over the world.

Euphrates is one of the major sources of the surface water in Iraq, so the study of quality and quantity of this river, its management and its remote sensing have become one of the major concerns.

It is important in the present time and in the future to try to take information and data for water uses of surface water as fast as possible using new fast techniques such as remote sensing. At some times or in some places, the use of remote sensing and satellite image analyses are more economical and safer in case of difficult, dangerous, or far places.

\section{Concepts and foundations of remote sensing}

Remote sensing is the science and art of obtaining information about an object, area, or phenomenon through the analysis of data acquired by a device that is not in contact with the object, area, or phenomenon under investigation (Lillesand and Kiefer [1]).

A digital image, obtained by a scanner system, is a regular grid array in which a digital number (DN) is assigned by a remote sensing system's detector, which is related to the parameter that is being measured. It is important to understand that DNs are arbitrary units which are used to indicate variation in radiance. Absolute radiance values may be obtained from the DNs by means of calibration graphs. Most remote sensing systems are multispectral and obtain data simultaneously in specific wavebands. LANDSAT TM, for example, obtains data in seven bands; thus a thematic mapper (TM) scene would have seven digital images associated with it. The spectral resolution of a remote sensing system is a measure of how narrow the wavebands are and how many of them are recorded (Gibson and Power [2]).

\section{Water quality index (WQI)}

Any river can be classified into various grades indicating the beneficial use(s) to which it can be put to. The grades are based on the permissible limits of relevant pollution parameters (water quality variables) or standards set by the various authorities. Depending on the quality of water in various stretches of a river, the river can be zoned according to stretch suitability for the beneficial use(s). The assigning of a class to a river reach is not simple. Only in rare cases are all the relevant variables found to be within the permissible limits of a given class. In other words, in most cases, the river water would be classified into one grade with regard to one set of variables and into another class with regard to another variable or set of variables. So, it would be appropriate to base river classification on the ranges of an index representing the integrating effect of the 
concentrations and important values of the relevant variables for a use. Whereas the concept of water quality index (WQI) is used as a management tool in water quality assessments by integrating the effect of specific parameters in determining the type and use of water in definite site of the river (Al-Saffar [3]).

The definition of the water quality index may be summarized as a unitless number on a scale from 0 to 100 . The better the water quality, the higher the value of the index. Very clean water has an index of 100 , and very polluted water has an index of 0 (Dojlido et al. [4]).

There are two main approaches for water quality index quantification - one based on absolute sub-indices, which are defined as the water quality formulas that their solution is independent of the water quality standard, and other water quality index is called relative sub-indices, which are formulas where their solution depends on the water quality standard (Khan et al. [5]).

The geometric mean formula was suggested by Bhargava as an absolute subindex which expressed as:

$$
W Q I=\left[\pi_{i=1}^{n} f i\left(P_{i}\right)\right]^{1 / n} \times 100
$$

where $f_{i}\left(P_{i}\right)$ is the sensitivity function for each variable including the effect of variable weight concentration which is related to a certain activity and varies from $0-1$ and $n$ is the number of variables (Bhargava [6]).

The Bhargava method can easily deal with relative parameters for different uses by using sensitivity functions curves which take the value between zero to one. The nature of the sensitivity functions is determined by the impact of a change in the value of the parameter on water quality as in figures 1 which represents the sensitivity function curves for irrigation use [chlorides $(\mathrm{Cl})$, electrical conductivity (EC), total dissolved solids (TDS), sodium adsorption ratio (SAR), hydrogen power $\left(\mathrm{p}^{\mathrm{H}}\right)$ and sulfates $\left.\left(\mathrm{SO}_{4}\right)\right]$. These curves are used to evaluate the quality of waters and give the importance of any parameter for a specific use; it also gives weight to every parameter. WQI according to Bhargava is also used to classify waters into five groups (Table 1) and to determine the WQI for each use of different water activities depending on the variables which affect water activity (Mahdi [7]).

Table 1: Water quality classification according to the Bhargava method (Mahdi [7]).

\begin{tabular}{|c|c|c|}
\hline Class & WQI Value & Water Quality \\
\hline I & $100-90$ & Excellent \\
\hline II & $89-65$ & Good \\
\hline III & $64-35$ & Acceptable \\
\hline IV & $34-10$ & Polluted \\
\hline V & Less than 10 & Severe Polluted \\
\hline
\end{tabular}



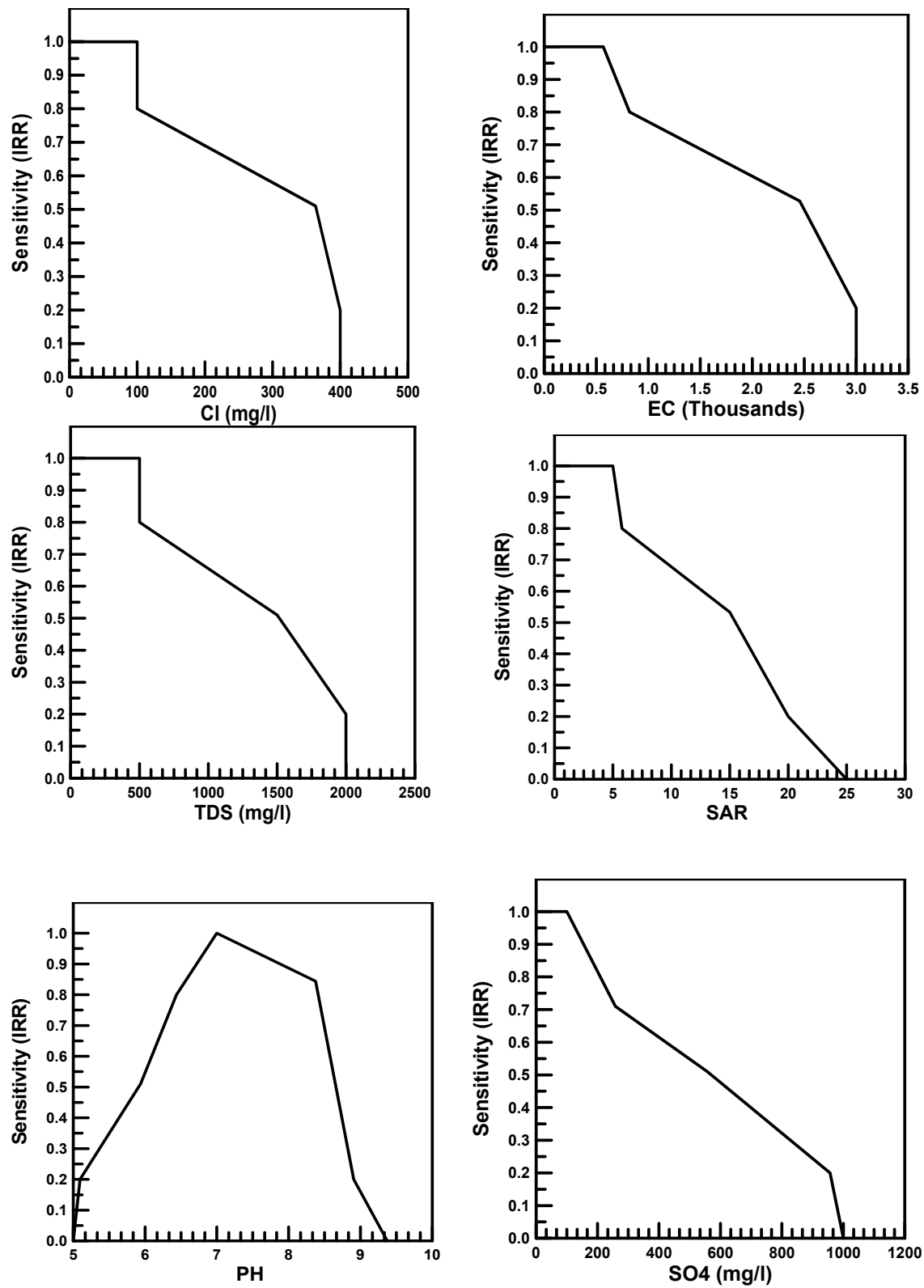

Figure 1: Sensitivity functions curves according to Bhargava for irrigation use (Bhargava [6]). 


\section{Calculations and results}

A LANDSAT satellite images were merged together to make one mosaic digital image of a map of Iraq consisting of three bands - 1, 2 and 3. This mosaic image was modified on Sunday 20:25:06 on 22nd November, 2009. The mosaic image was corrected geographically and georeferenced.

The width and height of the layer were 35005 and 32999 pixels. The upper left and lower right of latitude and longitude coordinates were (38.76333433, $37.41756692)$ and $(48.63190171,28.89314744)$ as seen in figure 2.

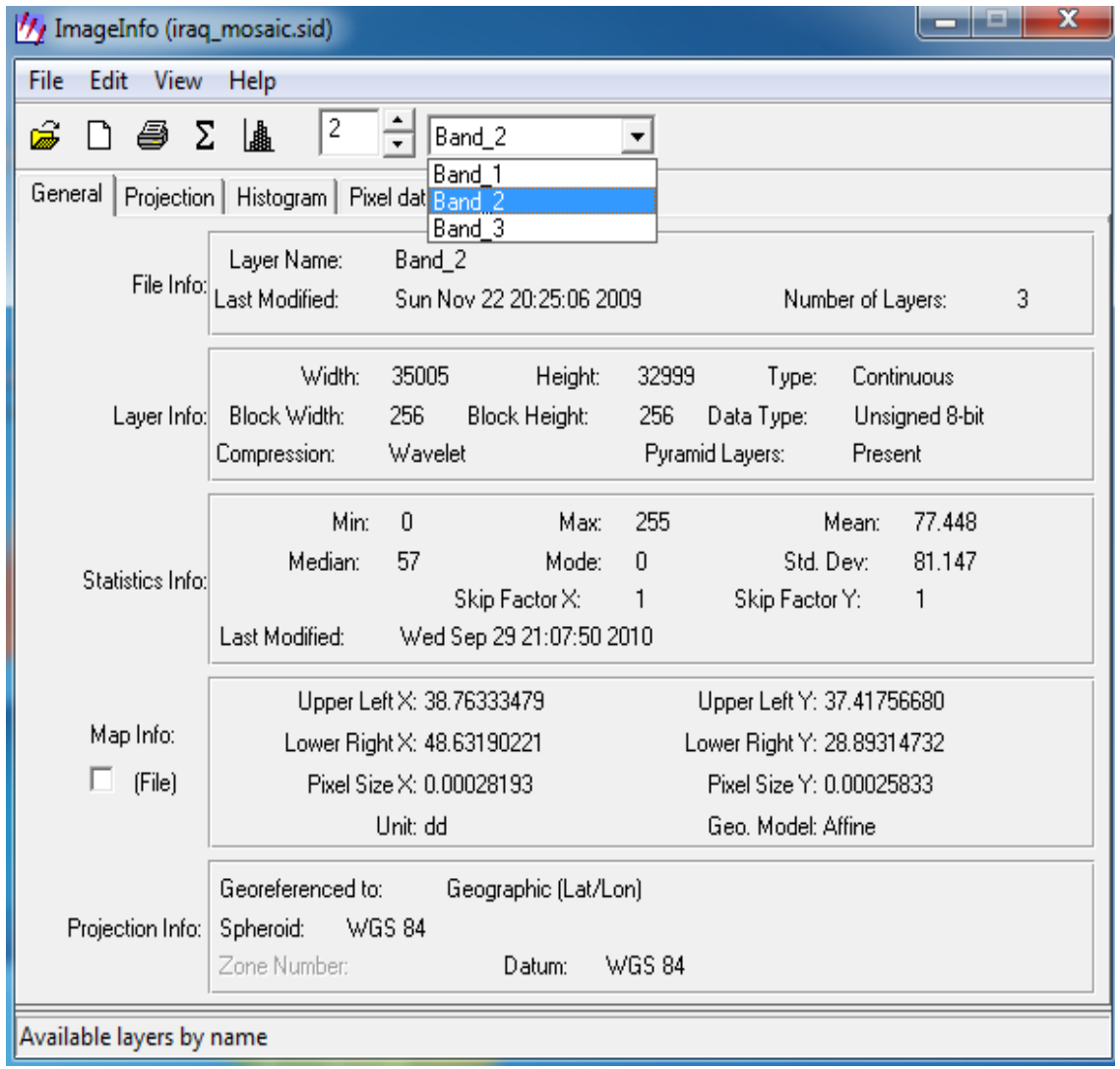

Figure 2: $\quad$ Image information for Iraq mosaic.

The coordinates of the sixteen stations of the Euphrates were projected and mapped on the mosaic LANDSAT image, as seen in figure 3. Signature editor technique in the software ERDAS Imagine 8.4 was used to find the digital numbers (DNs) at bands 1, 2 and 3 for each station along the Euphrates in the satellite image (Al-Bahrani [8]). 


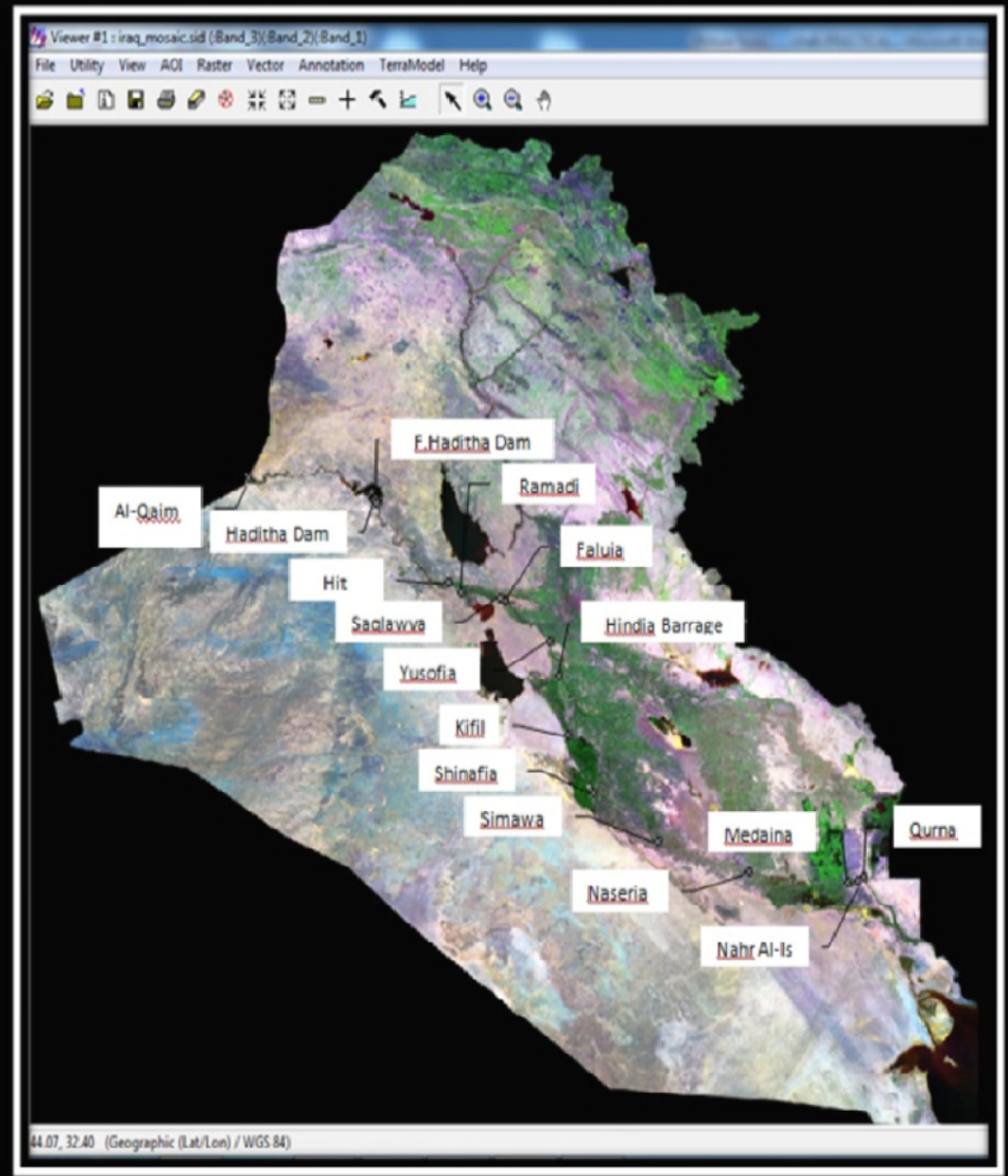

Figure 3: Euphrates River stations projected on Iraq Mosaic LANDSAT satellite image (Al-Bahrani [8]).

Table 2 illustrates the values of the digital numbers (DNs) in bands 1, 2, and 3 for the sixteen stations of the Euphrates. It is noticed that there is an increase in the DN for band 2 at Shinafia station because of the increase of chlorophyll in the water. Besides, the reason for increasing the DNs for bands 1,2 and 3 at Naseria station was increasing the turbidity in the water.

Microsoft Excel (2007) was adopted as a tool for the computation of irrigation water quality index (IWQI) for the sixteen stations along the Euphrates inside Iraqi land during the period from September to December, 2009 as shown in figure 4. 
Table 2: $\quad$ Digital numbers for Euphrates stations (Al-Bahrani [8]).

\begin{tabular}{|l|c|c|c|}
\hline \multirow{2}{*}{ Station } & \multicolumn{3}{|c|}{ Digital numbers } \\
\cline { 2 - 4 } & $\begin{array}{c}\text { Band 1 } \\
(0.45-0.52) \mu \mathrm{m}\end{array}$ & $\begin{array}{c}\text { Band 2 } \\
(0.52-0.60) \mu \mathrm{m}\end{array}$ & $\begin{array}{c}\text { Band 3 } \\
(0.63-0.69) \mu \mathrm{m}\end{array}$ \\
\hline Al-Qaim & 0 & 0 & 22 \\
\hline Forward Haditha Dam & 9 & 8 & 19 \\
\hline Haditha Dam & 8 & 12 & 3 \\
\hline Hit & 2 & 12 & 15 \\
\hline Ramadi & 0 & 15 & 31 \\
\hline Saqlawia & 10 & 22 & 47 \\
\hline Faluja & 9 & 20 & 37 \\
\hline Yosufia & 7 & 11 & 38 \\
\hline Hindia Barrage & 1 & 7 & 20 \\
\hline Kifil & 0 & 11 & 9 \\
\hline Shinafia & 7 & 50 & 34 \\
\hline Simawa & 13 & 23 & 77 \\
\hline Naseria & 37 & 47 & 24 \\
\hline Medaina & 7 & 21 & 42 \\
\hline Nahr Al-Is & 5 & 23 & 12 \\
\hline Qurna & 9 & & \\
\hline
\end{tabular}

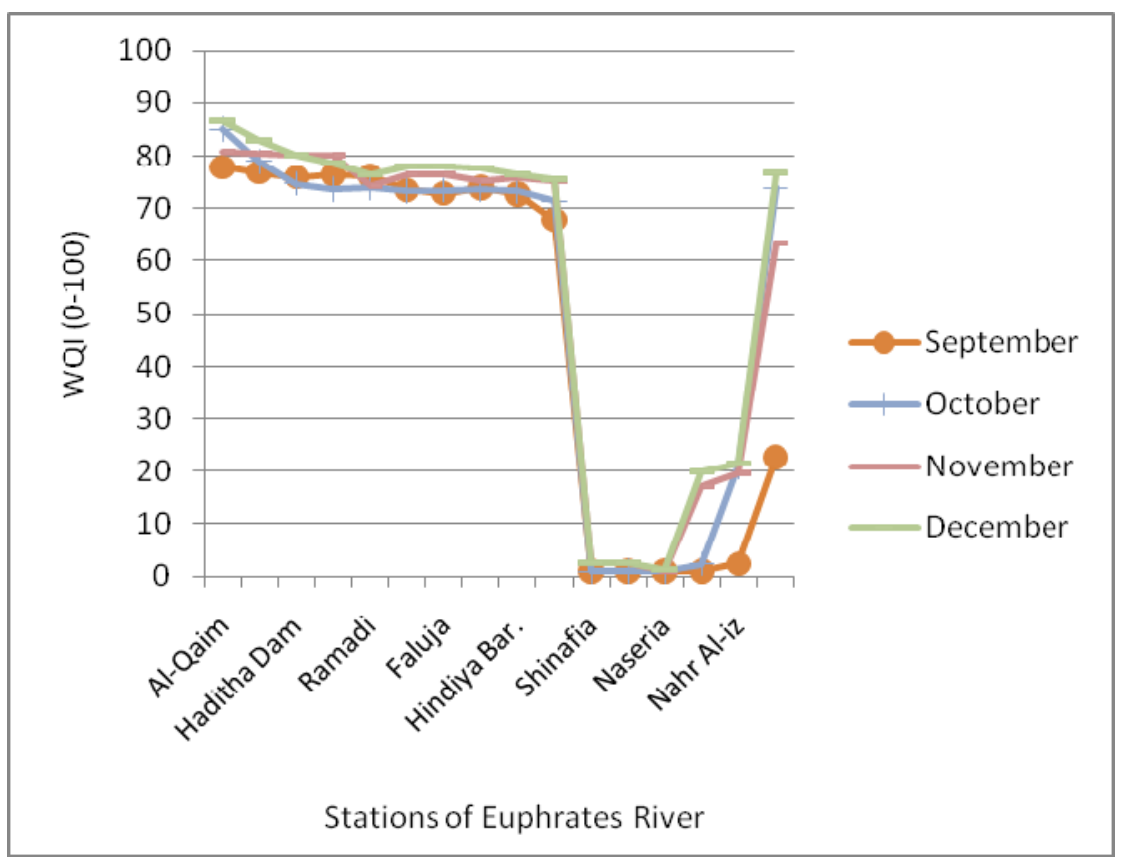

Figure 4: Water quality index (WQI) for irrigation use according to the Bhargava method for stations of Euphrates River during September to December, 2009. 
Correlation coefficients between the DNs in the three bands for Iraq mosaic LANDSAT satellite image and the water quality indices according to Bhargava method for the stations of Euphrates River were computed according to Pearson method at significant 0.05 and 0.01 as shown in table 3 . It was noticed that the correlation coefficients between the digital numbers of the satellite image in the first three bands and the water quality indices for the Euphrates stations were negative for all bands of the image. The correlation coefficients of DNs; at band 2 were always greater than the correlation coefficients of DNs at other bands. The largest value of correlation coefficient between the DNs in band 2 and WQIs according to the Bhargava method was in December, 2009, equal $(-0.814)$. From these results, it can be said that the digital numbers of the LANDSAT satellite image at band 2 gives the best relationship with the water quality index for irrigation use.

Table 3: Correlation coefficients of DNs and WQIs according to Bhargava method for the stations of Euphrates.

\begin{tabular}{|c|l|l|l|l|l|}
\hline Time & Band 1 & Band 2 & Band 3 & Bands 1+2 & $\begin{array}{c}\text { Bands } \\
\mathbf{1 + 2 + 3}\end{array}$ \\
\hline Sep-09 & -0.490 & $-0.707^{* *}$ & -0.222 & $-0.680^{* *}$ & $-0.527^{*}$ \\
\hline Oct-09 & $-0.519^{*}$ & $-0.793^{* *}$ & -0.187 & $-0.749 * *$ & $-0.549^{*}$ \\
\hline Nov-09 & $-0.546^{*}$ & $-0.801^{* *}$ & -0.234 & $-0.766^{* *}$ & $-0.585^{*}$ \\
\hline Dec-09 & $-0.541^{*}$ & $-0.814^{* *}$ & -0.207 & $-0.773 * *$ & $-0.574 *$ \\
\hline$* *$ Correlation is significant at the 0.01 level (2-tailed). \\
$*$ Correlation is significant at the 0.05 level (2-tailed). \\
\hline
\end{tabular}

\section{Regression equations}

Regression models of the WQIs on DNs at band 2 for the stations of the Euphrates at months of strong correlations at confidence 0.99 for the Bhargava method were found as seen in table 4 , where $B_{2}$ represents the digital numbers of the satellite image at band 2 . These regression models in table below could be used to find WQIs from the digital numbers of band 2 in the satellite image.

Table 4: Accepted regression models of WQIs according to the Bhargava method of Euphrates stations on digital numbers at band 2 of Iraq mosaic satellite image.

\begin{tabular}{|l|l|l|l|l|l|}
\hline Time & Regression model & $r^{2}$ & d.f. & $\begin{array}{c}\text { Test } \\
\text { function }\end{array}$ & $\begin{array}{c}\text { Tabulated } \\
F[0.99 ; 1, \text { d.f. }]\end{array}$ \\
\hline Sep-09 & $\mathrm{S} 9=82.50-1.86 \mathrm{~B}_{2}$ & 0.499 & 14 & 13.96 & 8.90 \\
\hline Oct-09 & $\mathrm{O} 9=89.93-2.00 \mathrm{~B}_{2}$ & 0.628 & 14 & 23.60 & 8.90 \\
\hline Nov-09 & $\mathrm{N} 9=91.19-1.97 \mathrm{~B}_{2}$ & 0.644 & 14 & 25.35 & 8.90 \\
\hline Dec-09 & $\mathrm{D} 9=94.68-2.04 \mathrm{~B}_{2}$ & 0.660 & 14 & 27.17 & 8.90 \\
\hline
\end{tabular}




\section{Building the colored model according to Bhargava method}

With the assistance of the software ERDAS Imagine 8.4, isodata unsupervised classification was used to determine the water areas on the Iraq mosaic satellite image. The Euphrates River in the satellite image of the Iraq mosaic was colored according to Bhargava classifications for irrigation use of water quality by building regression models for digital numbers (DNs) of band 2 on water quality index (WQI). It was found that the linear regression model in December, 2009 as seen in equation (2), was the best model because it had the biggest coefficient of determination $\left(r^{2}\right)$ and the biggest test function:

$$
D N 2=36.8215-0.3229 \text { BDec } 9
$$

where $D N 2$ represented the digital numbers for band 2 at the Iraq mosaic, and $B D e c 9$ represented Bhargava WQIs for the Euphrates stations in December, 2009. The water areas in the satellite image were classified into five colors depending on the five classifications of water quality index according to Bhargava method, as shown in table 5.

Table 5: Colored classifications for the water of the Euphrates at the Iraq mosaic satellite image according to Bhargava water quality classifications.

\begin{tabular}{|c|c|c|}
\hline Bhargava classifications & Water quality index & Colored classifications \\
\hline Severe polluted & $0-9$ & Brown \\
\hline Polluted & $10-34$ & Violet \\
\hline Acceptable & $35-64$ & Green \\
\hline Good & $65-89$ & Orange \\
\hline Excellent & $90-100$ & Turquoise \\
\hline
\end{tabular}

The data at table 5 were entered in equation (2) and used in the Knowledge Engineer Classifier at the software ERDAS Imagine 8.4 so as to build the colored model of the water at the Euphrates River in the satellite image in December, 2009, as shown in figure 5.

To check the colored model of the WQI of the Euphrates according to Bhargava classifications that was built with the assistance of the Knowledge Engineer Classifier technique from the Software of ERDAS Imagine 8.4, the Euphrates stations was projected onto the satellite image of the colored model, a comparison was done between their mathematical values of water quality index according to the Bhargava method in December, 2009 and the colors of the model at each point on the image. If the values of WQI locates in the same or nearby classifications of the colored model, this means that the colored model was appropriate for spatial prediction at the Euphrates inside Iraqi lands at that time. 


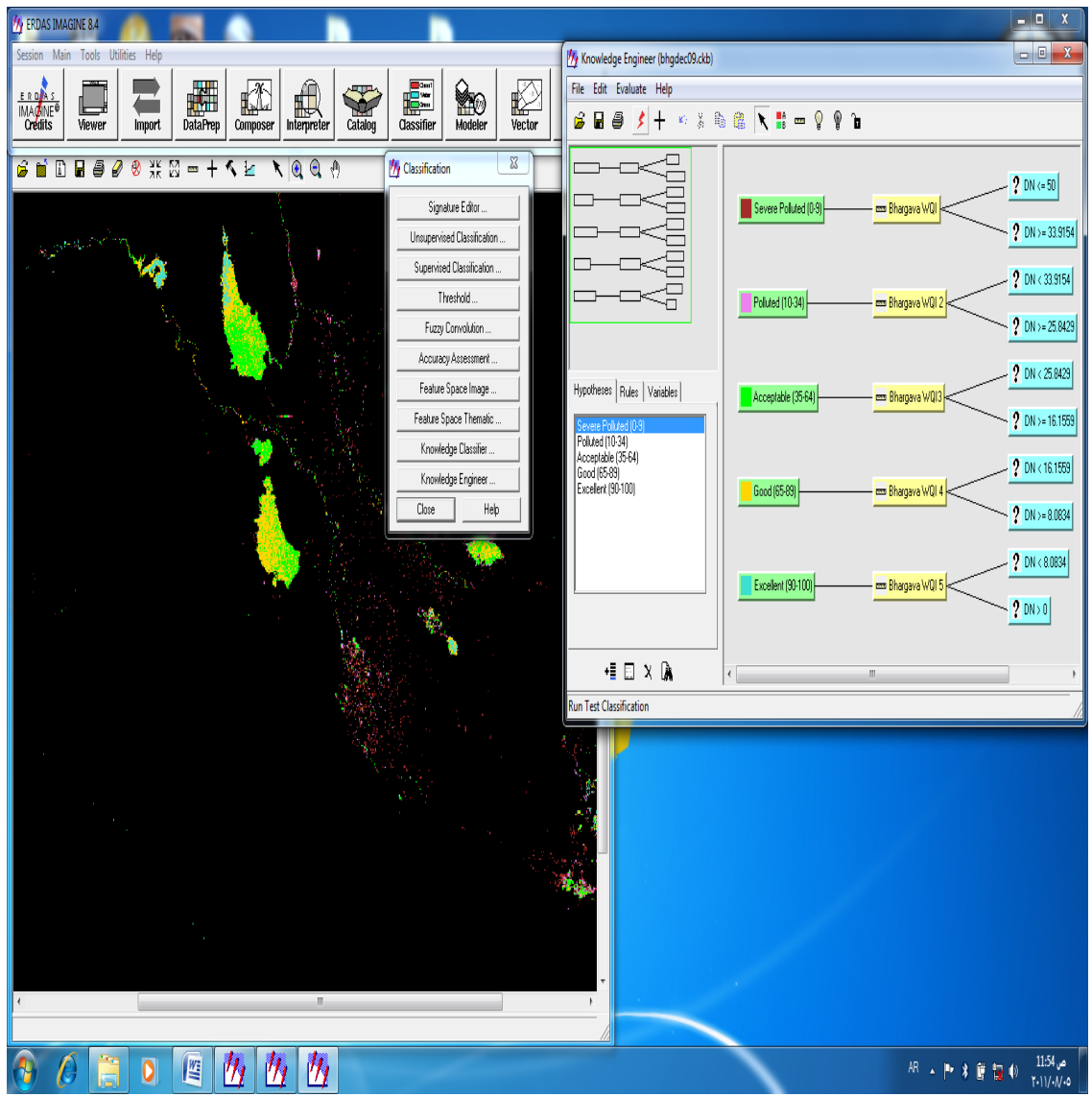

Figure 5: The colored model of WQI according to Bhargava classifications in December, 2009.

As shown in figure 6, the stations of Al-Qaim, Forward Haditha Dam, Haditha Dam and Hit was projected onto the satellite image of Bhargava colored model in December, 2009. It was noticed that all stations were located on orange spots, which represented the Good classification according to the Bhargava method (table 4). Also, it was noticed that the WQIs according to Bhargava for the four stations in December, 2009 were $(87,83,80$, and 79) sequentially, and these values were classified as Good (65-89) according to Bhargava classifications in table 1 . The same thing happened for the next twelve stations where their water quality indices located on the same color of Bhargava classifications and this ensured the appropriateness of the colored model for the spatial prediction of water quality index for irrigation use for the river of Euphrates. 

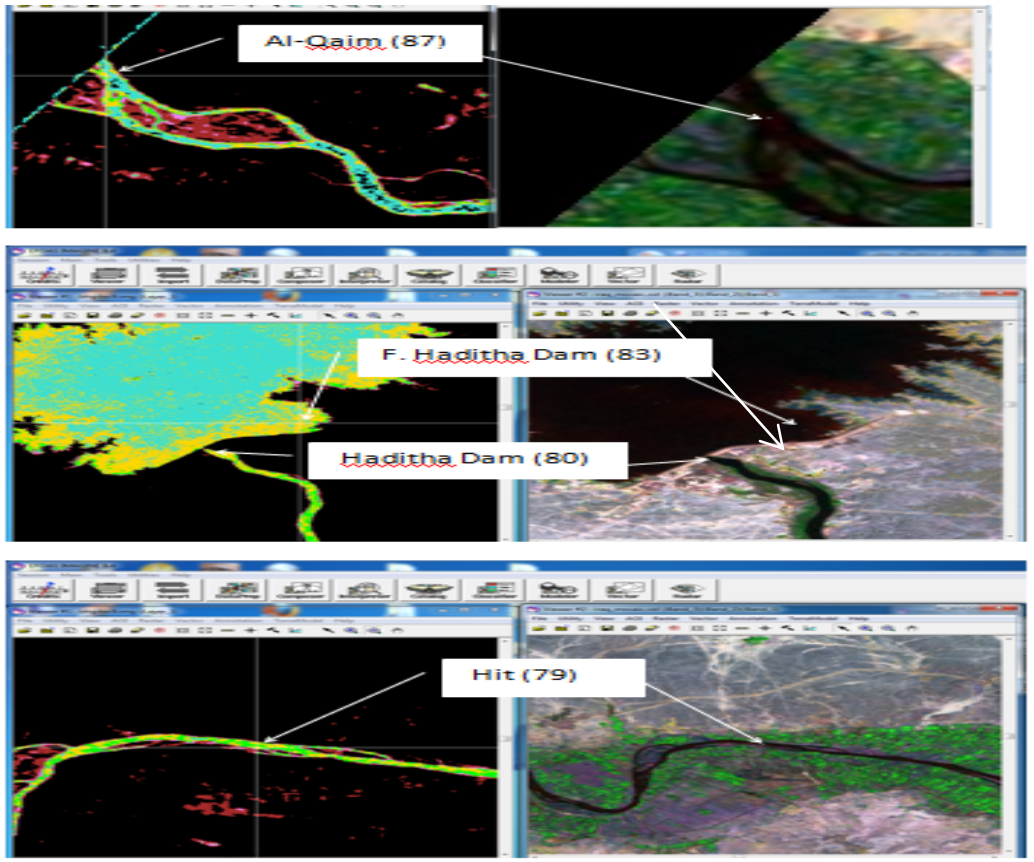

Figure 6: Locations of Al-Qaim hit stations and their WQIs on the Bhargava colored model.

\section{Conclusion}

The following rules were observed in this work: (1) the relationship between the water quality index and the digital number for the first three bands of LANDSAT satellite image was negative and the correlation was stronger between the water quality index and the digital number for band 2 most of the time, (2) the correspondence between the real values of the water quality indices for the sixteen stations of the Euphrates with the colored model in the satellite image proved the success of the colored model to predict the water quality index at any location along the river inside the Iraqi lands, and (3) the water quality indices according to the Bhargava method were classified as Good for the first ten stations of the Euphrates from Al-Qaim to Kifil while the other six stations fluctuated in their classifications between Good and Severely Polluted during the steady period. The real reason for these fluctuations was the increase in concentrations of chlorides and TDS as a result of mixing with drainage waters.

\section{References}

[1] Lillesand, T. M. and Kiefer, R. W., Remote Sensing and Image Interpretation, John Wiley \& Sons, USA, second edition, 1987. 
[2] Gibson, P. J. and Power C. H., Introductory Remote Sensing: Digital Image Processing and Processing, Routledge, USA and Canada, First Edition, 2000.

[3] Al-Saffar, A. E. A, Proposed Water Quality Management system for Tigris River, PhD, thesis, Civil Engineering, University of Baghdad, Iraq, 2001.

[4] Dojlido, J., Raniszewski, J. and Woysie, C. J., Water Quality Applied To Rivers In The Vistula River Basen In Poland, Environmental Monitoring and Assessment, vol. 33, pp. 33-42, 1994.

[5] Khan, F., Husain, T. and Lumb, A., Water Quality Evaluation And Trend Analysis In Selected watersheds Of The Atlantic Region Of Canada, Journal Environmental Monitoring and Assessment, Vol. 88: 221-242, Kluwer Academic Publishers, Netherlands, 2003.

[6] Bhargava, D.S., Use of Water Quality Index for River Classification and Zoning of Ganga River, Environmental Pollutants, Series B, England, pp. 52-67, 1983.

[7] Mahdi, W. S. K., Construct A Program For Irrigation And Drinking Water Suitability Of Tigris And Euphrates Rivers, MSc thesis, Water Resources department, Engineering College, University of Baghdad, Iraq, 2009.

[8] Al-Bahrani, H. S., Modeling the outputs of mathematical models and satellite image analysis to predict irrigation usability for Euphrates, $\mathrm{PhD}$. thesis, Environmental Engineering Department, University of Baghdad, Iraq, 2012 . 